\title{
Determinação das castas em Scaptotrigona postica (Latreille) (Hymenoptera, Apidae, Meliponini): diferenciação do ovário
}

\author{
Thaís da Cruz Alves dos Santos 1, 2 \\ Carminda da Cruz-Landim ${ }^{1}$
}

\begin{abstract}
Caste determination in Scaptotrigona postica (Latreille) (Hymenoptera, Apidae, Meliponini): The ovarian differentiation. Both castes of Scaptotrigona postica (Latreille, 1804) possess four ovarioles in each ovary. Queen and workers have the same ovarian development during the larval life, but in the late larval stage the queen ovary become larger. During pupation a higher rate of cell division is observed in queen ovarioles and a higher rate of cell death in workers. Newly emerged workers have short ovarioles with differentiated germarium and vitellarium while queens have very long ovarioles with only germarium. Caste determination in this species of bee is trophic, but the food does not differ in quality, only in quantity. The food differences only become effective by the end of larval stage when the queen larvae have the opportunity of eat more. In this way the ovary differentiation, between workers and queens, in this species, only occurs from the end of larval stage, mainly during pupation. Although the ovaries of workers are smaller, they are precocious in relation to queens, since nurse workers, 5 to 20 days, old may lay eggs. The eggs laid by the workers may be trophic or functional. These eggs may be distinguished by the aspect of the yolk. Older forager workers have degenerated ovaries.

KEY WORDS. Stingless bee, castes, ovary differentiation, cell division, cell death
\end{abstract}

Nas colônias de abelhas eussociais ocorre uma divisão do trabalho reprodutivo entre as fêmeas, segundo a qual a rainha é responsável pela produção de novos indivíduos e as operárias por todos os serviços necessários para a manutenção e defesa da colônia (RibBANDS 1953; MichenER 1974; FreE 1980).

As diferenças que se estabelecem entre rainhas e operárias, para o exercício dessas funções, são de várias naturezas e abrangem a morfologia, a fisiologia e o comportamento, e resultam em um dimorfismo acentuado entre as duas castas. O desenvolvimento diferencial dos ovários é uma das mais marcantes características deste dimorfismo (SNODGRASS 1956; REGINATO \& CRUZ-LANDIM 1998).

$\mathrm{Na}$ maioria das espécies de abelhas eussociais o determinante visível da diferenciação das castas é a diferente alimentação das larvas de rainhas e operárias. A ação da alimentação diferencial nos tecidos deve se dar através de mecanismos fisiológicos, envolvendo ação hormonal, sendo mais conhecida a atuação do hormônio juvenil, que funciona como um hormônio morfogenético (DIXON \& SHUEL 1963; BEETSMA 1979; REMBOLD 1987; RACINSKY \& HARTFELDER 1990; 1991; RACHINSKY \& ENGELS 1995).

1) Departamento de Biologia, Instituto de Biociências de Rio Claro, Universidade Estadual Paulista. Caixa Postal 199, 13506-900 Rio Claro, São Paulo, Brasil.

E-mail: tcsantos@yahoo.com; cclandim@rc.unesp.br

2) Bolsista CNPq.

Revta bras. Zool. 19 (3): $703-714,2002$ 
A maneira de alimentar as larvas, bem como o alimento fornecido, é diferente em Apis mellifera (Linnaeus, 1758) e nos Meliponini. Em A. mellifera, a alimentação das larvas é progressiva e aquelas destinadas a serem rainhas são alimentadas com geléia real, enquanto as que serão operárias, após o segundo ou terceiro dia recebem mistura de mel, pólen e geléia real. Esta diferença alimentar provoca, em $A$. mellifera, degeneração dos ovários a partir do terceiro dia de vida larval (REGINATO \& CRUZ-LANDim 2001, 2002). Em alguns Meliponini, e.g. Scaptotrigona postica (Latreille, 1804), a alimentação é massiva e a diferença entre operária e rainha é determinada pela quantidade de alimento ingerida a qual é maior na rainha, e só se concretiza no final do desenvolvimento larval.

Por outro lado, em A. mellifera as operárias adultas não desenvolvem os ovários na presença da rainha (RIBBANDS 1953; FREE 1980), mas na maior parte das espécies de Meliponini estas podem desenvolvê-los e botar ovos mesmo na presença desta (SAKAGAMI et al. 1963; SAKAGAMI \& ZUCCHI 1966). Alguns desses ovos, os ovos tróficos, servem de alimento para a rainha (SAKAGAMI et al. 1963; SAKAGAMI 1982) enquanto outros, os ovos funcionais, se desenvolvem e originam machos (BeIG 1972; SiLva 1977; Bego 1982; SAKAGAmi 1982; SommeiJer et al. 1990, 1999; VAN VEEN et al. 1990; SOMMEIJER \& BUREN 1992).

Em A. mellifera as larvas de operárias e rainhas têm, a princípio, o mesmo número de ovaríolos nos ovários, mas muitos destes degeneram resultando que as rainhas adultas apresentam centenas de ovaríolos por ovário e as operárias 2 a 12 apenas. Em $S$. postica, tanto as operárias como as rainhas têm quatro ovaríolos por ovário, mas os da rainha são muito mais longos que os das operárias (CRUZ-LANDIM 2000).

Tendo em vista o exposto, o objetivo do presente trabalho foi investigar em que momento se estabelecem as diferenças no desenvolvimento ovariano entre operárias e rainhas de Scaptotrigona postica, se durante a vida larval ou durante a pupação e quais os mecanismos que levam a essas diferenças.

\section{MATERIAL E MÉTODOS}

Os espécimes de Scaptotrigona postica foram coletados de colônias mantidas no Biotério do Instituto de Biociências da Universidade Estadual Paulista, Rio Claro, São Paulo.

Utilizaram-se operárias em diferentes estágios de desenvolvimento: larvas em último estágio, pré-pupas, pupas de olhos branco, rosa, vermelho, marrom e preto, pupas com pigmentação corporal, adultas recém-emergidas, nutridoras e campeiras. Para rainhas foram coletados os estágios de larvas, pré-pupas, pupas de olhos marrons e adultas recém-emergidas. A pigmentação das pupas, primeiro dos olhos e posteriormente do restante do corpo foi utilizada como medida do avanço do desenvolvimento.

Os abdomes das pupas e indivíduos adultos foram separados do resto do corpo e fixados em Dietrich por 24 horas. As larvas e pré-pupas foram fixadas inteiras no mesmo fixador, pelo mesmo tempo. Em seguida o material foi desidratado em série alcoólica de concentrações crescentes até 95\%. 
A inclusão foi feita em historesina Leica, seguindo o protocolo do fabricante, para preparação de lâminas histológicas. Secções com a espessura de $5 \mu \mathrm{m}$ foram coradas com Hematoxilina de Harris e Eosina aquosa e montadas em bálsamo do Canadá, observadas e fotografadas em fotomicroscópio.

\section{RESULTADOS}

\section{Desenvolvimento do ovário nos imaturos}

Os resultados mostraram que, durante a vida larval, rainha e operária têm o mesmo desenvolvimento ovariano. No último estágio larval de ambas as castas os ovários já estão constituídos pelos quatro ovaríolos bem diferenciados. Nestes pode-se distinguir um pedúnculo basal, futuro oviduto lateral, formado por células finas e longas, com núcleos basais, as quais formarão o epitélio dos ovidutos. Nos cortes longitudinais estas células aparecem dispostas em camadas transversais, superpostas, com os núcleos localizados na periferia (Fig. 1A). Na região apical dos ovaríolos estão presentes células arredondadas, com núcleos grandes consideradas como células germinativas, intercaladas por células com núcleos pequenos, as células somáticas. Os quatro ovaríolos são conjuntamente envoltos por camadas de células somáticas achatadas formando uma cápsula.

Durante o desenvolvimento dos ovários nas pupas, tanto de operárias como de rainhas, observam-se divisões celulares e morte celular. Estas divisões e mortes ocorrem tanto nas células germinativas como nas somáticas (Fig. 1A, B). As divisões celulares nos ovários das operárias nos estágios de pupas de olhos rosa e marrom podem ser vistas nas células do pedúnculo do ovaríolo (Fig 1A) e nas células no interior deste (Fig. 1B). Contudo, na região apical dos ovaríolos a taxa de morte celular representada por células com núcleos picnóticos é maior do que a taxa de divisões (Fig. 1B).

Até a pré-pupa os ovários de operárias e rainhas são bastante parecidos, mas a partir daí os da rainha apresentam-se bem mais longos.

Nos ovaríolos de pupas de operárias com olhos marrons já se distinguem na base do ovário cistos ovarianos (Fig. 1C) e células ovocíticas (Fig. 1C, D). Esta condição é ainda mais acentuada nas pupas com pigmentação no corpo onde em alguns casos o ovócito já pode ser distinguido das células nutridoras, caracterizando o início da diferenciação do vitelário.

Nas rainhas a diferenciação do ovário segue o mesmo padrão, mas o crescimento dos ovaríolos é maior e estes tendem a enovelar-se na região apical (Fig. 2A). Nestas é também possível observar divisões celulares no pedúnculo do ovaríolo (Fig. 2B) e no interior deste (Fig. 2C), mas a taxa é maior que nas operárias e não se observa morte celular no seu interior. Algumas células com núcleos picnóticos podem ser observadas no pedúnculo ou na membrana peritoneal do ovaríolo (Fig. 2B).

A tabela I mostra comparativamente as diferenças no desenvolvimento ovariano de operárias e rainhas durante a fase imatura.

\section{Desenvolvimento dos ovários pós-emergência}

Na rainha recém-emergida os ovaríolos aparecem muito longos, mas a maior parte destes é constituída pelo filamento terminal, apical, que não contém células germinativas no interior (Fig. 3A). Somente a região basal e mediana contém estas 


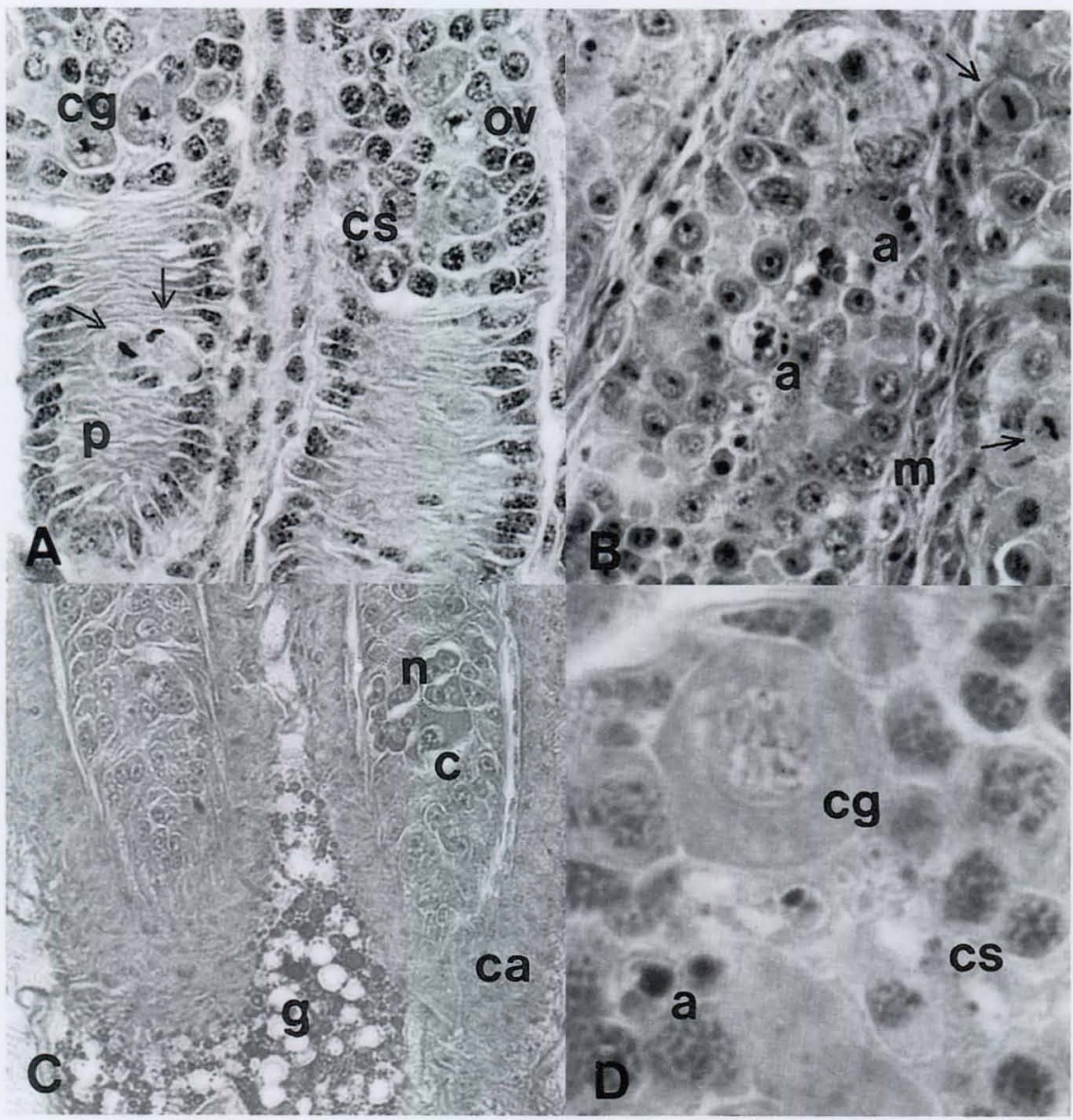

Fig. 1. Ovários de operárias de Scaptotrigona postica. (A) Porção basal do ovário de pupa de olho rosa vendo-se o contato entre os ovaríolos (ov) e o seu pedúnculo (p). Notar no ovaríolo, células germinativas (cg) e somáticas (cs) e no pedúnculo (p) divisões celulares (setas); (B) porção apical de ovaríolos vendo-se morte celular (a) e divisões celulares (setas); (C) porção basal de ovariolos de pupa de olho marrom vendo-se cistos (c) de células germinativas; (D) células germinativas $(\mathrm{cg})$, células somáticas (cs) e morte celular (a) intra ovariolar em pupa de olho marrom. (g) Corpo gorduroso, (ca) cápsula, (m) membrana peritoneal dos ovaríolos, (n) células nutridoras.

células (Fig. 3A, B, C). Nesta fase observam-se, principalmente na região mediana, muitas células em divisão (Fig. 3B). Na região basal dos ovaríolos estão presentes numerosos cistos (Fig. 3C).

Quando se comparam os ovários de operárias e rainhas recém-emergidas verifica-se a ausência nas primeiras do filamento terminal longo (Fig. 4A) e no interior do ovaríolo, várias células com núcleos picnóticos, indicando morte celular (Fig. 4A, 


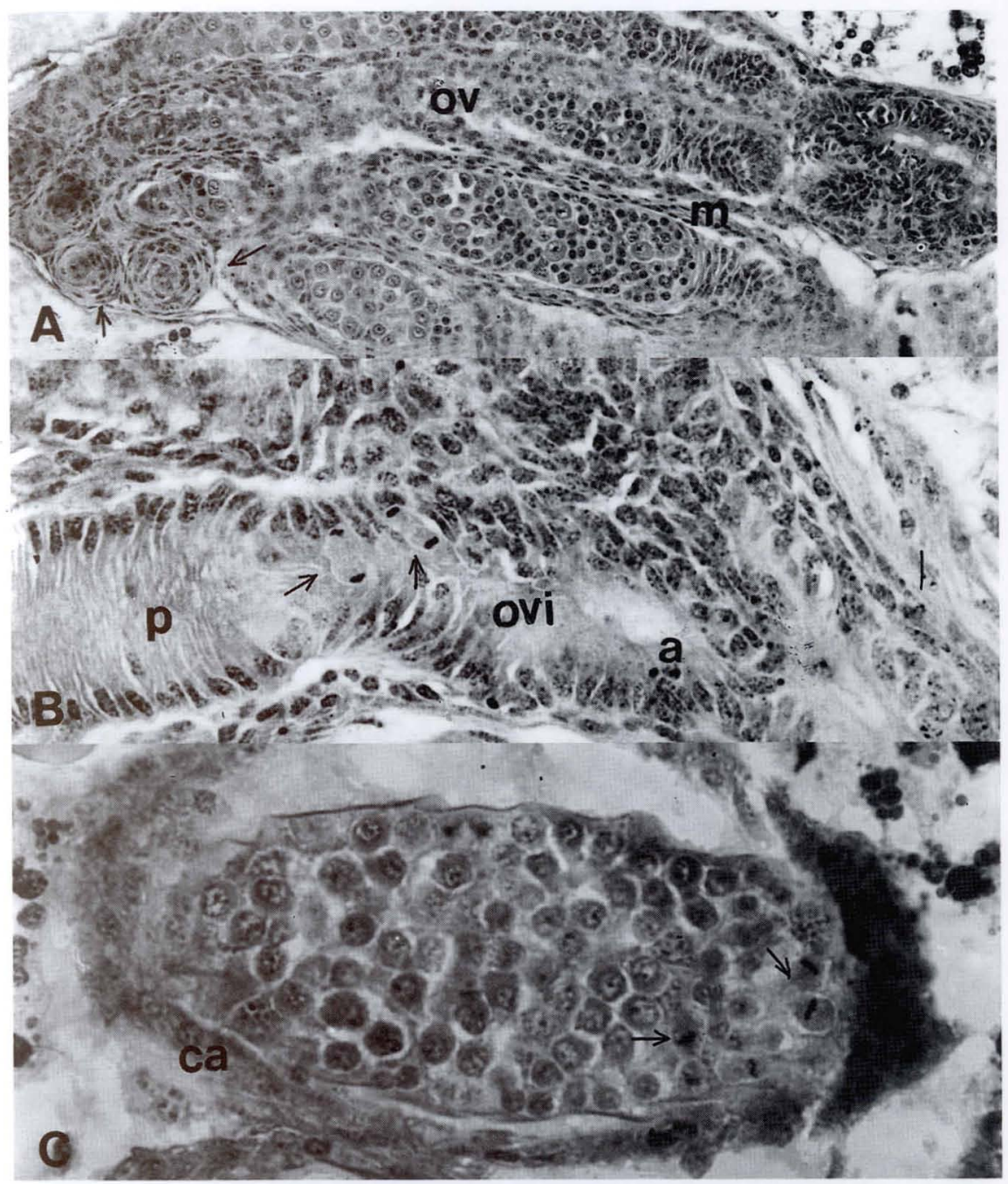

Fig. 2. Ovários de rainha de Scaptotrigona postica. (A) Ovário de pupa de olho rosa vendo-se o início do enrolamento distal (setas) dos ovaríolos (ov); (B) porção basal do ovário de pupa de olho rosa vendo-se divisões celulares (setas) no pedúnculo $(p) ;(C)$ porção apical de um ovaríolo de pupa de olho marrom vendo-se divisões celulares (setas). (ca) Cápsula, (m) membrana peritoneal, (ovi) oviduto, (a) morte celular.

B). Entre as células em processo de morte, encontram-se também células germinativas em divisão (Fig. 4B). Nas rainhas não se observam mortes celulares (Fig. 4C).

Em algumas operárias recém-emergidas os ovaríolos já apresentam germário e vitelário diferenciados, neste último as câmaras nutridoras e ovocíticas apresentam-se bem evidentes. No entanto, as operárias recém-emergidas ainda não apresentam ovócitos vitelogênicos. Estes estão presentes nas operárias nutridoras e campeiras. 


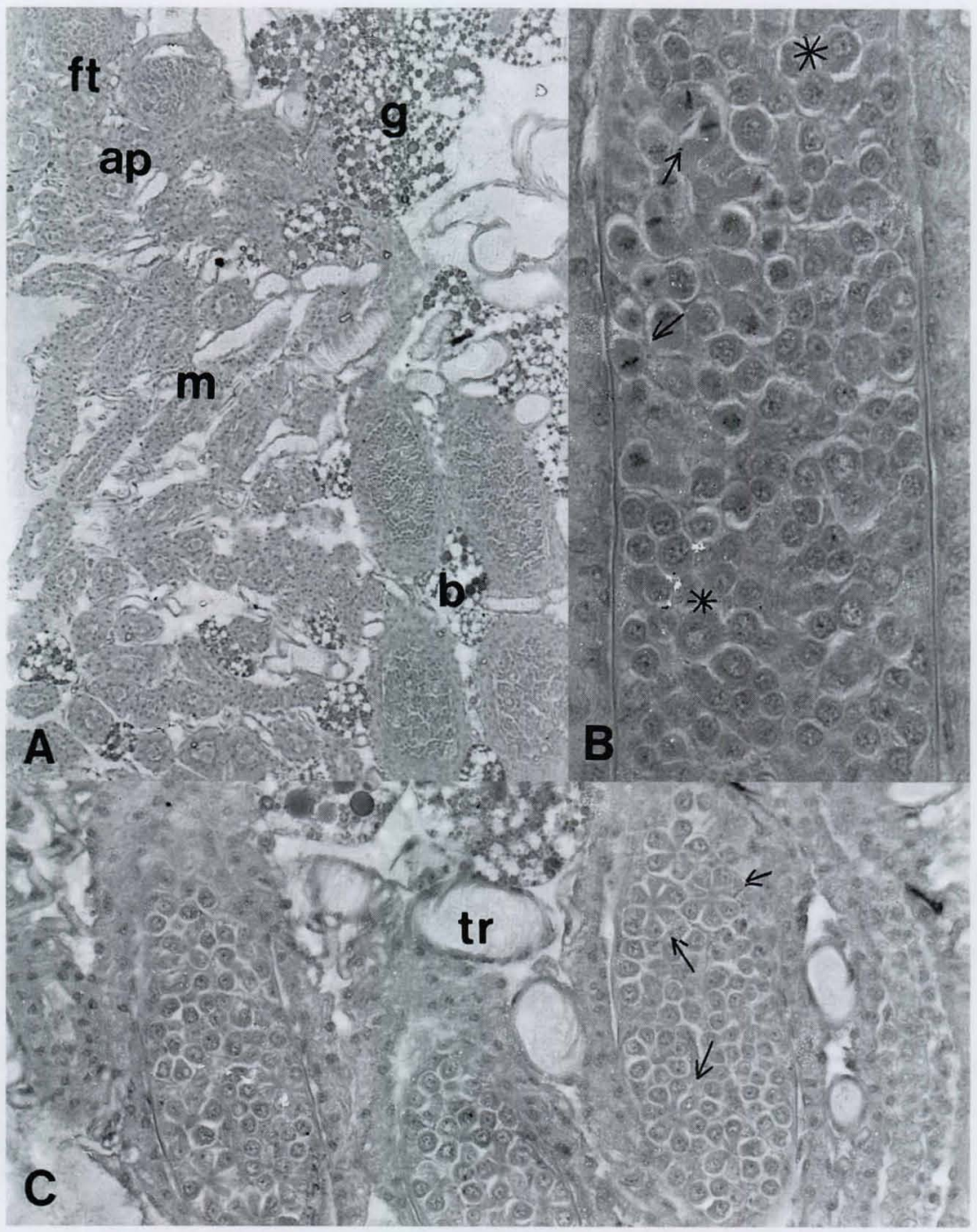

Fig. 3. Ovários de rainha de Scaptotrigona postica recém-emergida. (A) Ovário com ovaríolos muito longos e convolutos vendo-se a porção basal dos ovaríolos (b), a região mediana (m) e a maior parte constituída pelo filamento terminal, apical (ap); (B) região mediana de um ovaríolo mostrando divisões celulares (setas) e início da formação dos cistos (asteriscos); (C) região basal dos ovariolos vendo-se numerosos cistos (setas). (tr) Traquéias, (g) corpo gorduroso, (ft) filamento terminal.

Nas operárias nutridoras alguns ovócitos vitelogênicos, praticamente maduros, apresentam os grãos de vitelo dispersos e vacuolizados, ou seja, com regiões não coradas geralmente centrais (Fig. 5A), enquanto outros os apresentam mais concentrados e sem vacuolização. 
Em geral, os ovários das operárias campeiras, apresentam-se em fase de regressão, mas em algumas operárias desta classe ainda apresentaram ovócitos pré-vitelogênicos (Fig. 5B) e vitelogênicos (Fig. 5C). Nestas operárias os ovócitos vitelogênicos contêm vitelo formado por grânulos de tamanho variado, não vacuolizado, contornos bem definidos e em grande quantidade (Fig. 5C).

Nas operárias campeiras sempre se encontraram, na base do ovário, corpos lúteos (Fig. 5B, C) que resultam da degeneração das células foliculares, pós-ovulação. A tabela I mostra as diferenças entre os ovários das castas no adulto.

Tabela I. Comparação entre o desenvolvimento dos ovários em operárias e rainhas de Scaptotrigona postica.

\begin{tabular}{|c|c|c|}
\hline Fases & Operária & Rainha \\
\hline Desenvolvimento ovariano & $\begin{array}{l}\text { - Contínuo } \\
\text { - Ficam estacionários ou sofrem decréscimo }\end{array}$ & $\begin{array}{l}\text { - Continuo, maiores em relação à operária } \\
\text { - Crescem e se enovelam nas } \\
\text { extremidades distais }\end{array}$ \\
\hline Divisão celular & $\begin{array}{l}\text { - Taxa baixa } \\
\text { - Maior ocorrência na parte basal dos ovariolos }\end{array}$ & $\begin{array}{l}\text { - Taxa alta } \\
\text { - Presente ao longo de todo o ovariolo }\end{array}$ \\
\hline Morte celular & $\begin{array}{l}\text { - Taxa alta } \\
\text { - Maior ocorrência no ápice dos ovariolos }\end{array}$ & $\begin{array}{l}\text { - Taxa baixa } \\
\text { - Raramente presente ao longo dos } \\
\quad \text { ovariolos } \\
\text { - Presente em células somáticas }\end{array}$ \\
\hline Comprimento dos ovários & $\begin{array}{l}\text { - Crescimento contínuo até o fim da fase larval } \\
\text { - Regressāo ao longo da pupação }\end{array}$ & $\begin{array}{l}\text { - Crescimento contínuo até o indivíduo } \\
\text { emergir } \\
\text { - Continua após a emergência }\end{array}$ \\
\hline Diferenças no adulto & $\begin{array}{l}\text { - Recém-emergidas com um ou dois folículos } \\
\text { desenvolvidos } \\
\text { - Amadurecimento precoce dos folículos } \\
\text { - Ovos maduros na nutridora } \\
\text { - Produção de dois tipos de ovos (tróficos e } \\
\text { funcionais). Um ou dois ovos durante a vida } \\
\text { - Ovário degenera na operária campeira }\end{array}$ & $\begin{array}{l}\text { - Recém-emergidas sem folículos } \\
\text { diferenciados, sem diferenciação do } \\
\text { vitelário. Com numerosos cistos no } \\
\text { ovário } \\
\text { - Ovaríolos longos }\end{array}$ \\
\hline
\end{tabular}

\section{DISCUSSÃO}

A determinação das castas nesta espécie de abelha é trófica, tanto quanto em Apis mellifera, no entanto, o alimento dado às larvas de operárias e rainhas não difere em qualidade, mas apenas em quantidade. Os alvéolos onde são criadas as rainhas são maiores e, portanto, contém mais alimento. Como o total do alimento está à disposição da larva desde o início, quando as larvas de operária já esgotaram suas reservas, as de rainha ainda não, o que faz com que a diferenciação alimentar, diferentemente de $A$. mellifera, na qual ocorre a partir do segundo ou terceiro dia de vida larval, seja neste caso, tardio, apenas no último instar.

Em Apis mellifera as rainhas têm ovários com muitos ovaríolos longos (cerca de cento e oitenta por ovário) e as operárias com poucos ovaríolos curtos (de dois a doze por ovário). Nesta espécie o desenvolvimento ovariano começa igual em operárias e rainhas e mortes celulares provocam o desaparecimento de ovaríolos ao longo da vida larval da operária (REGINATO \& CRUZ-LANDIM 2001, 2002). 


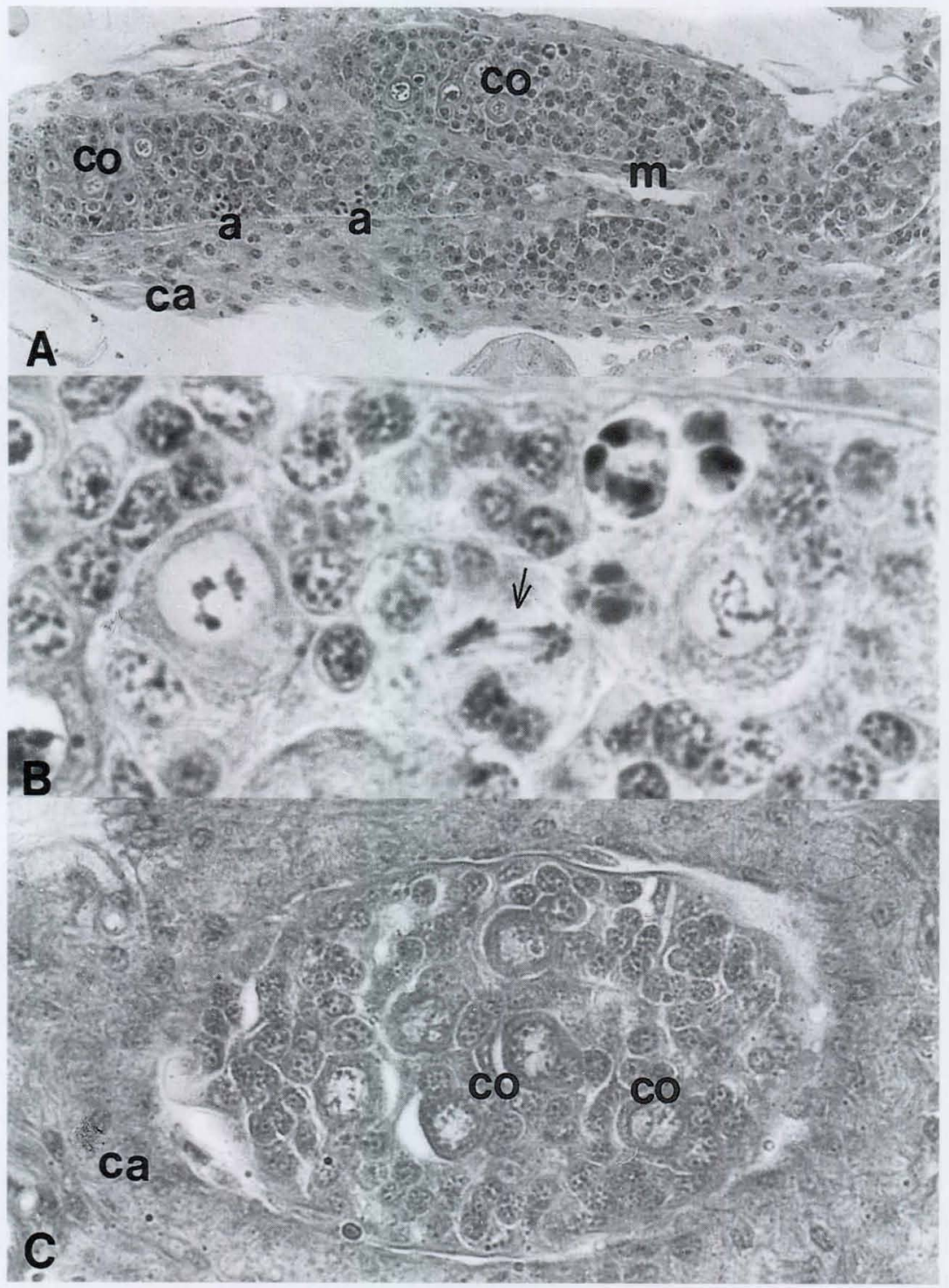

Fig. 4. Ovários de operárias e rainhas de Scaptotrigona postica recem-emergidas. (A) Ovário de operária recém-emergida vendo-se células ovocíticas (co) e regiōes de morte celular (a); (B) ampliação da região apical de um ovariolo de operária, mostrando detalhes das células; (C) porção basal de um ovaríolo de rainha vendo-se células ovocíticas (co). (ca) Cápsula, (m) membrana peritoneal, (setas) divisão celular.

No caso de $S$. postica, o desenvolvimento é igual até o fim da fase larval, quando termina a fase de alimentação e se caracteriza a maior ingestão de alimento pela rainha. Portanto, em Apis os ovários das rainhas e operárias começam a se diferenciar precocemente porque as diferenças na alimentação começam cedo e em

Revta bras. Zool. 19 (3): $703-714,2002$ 


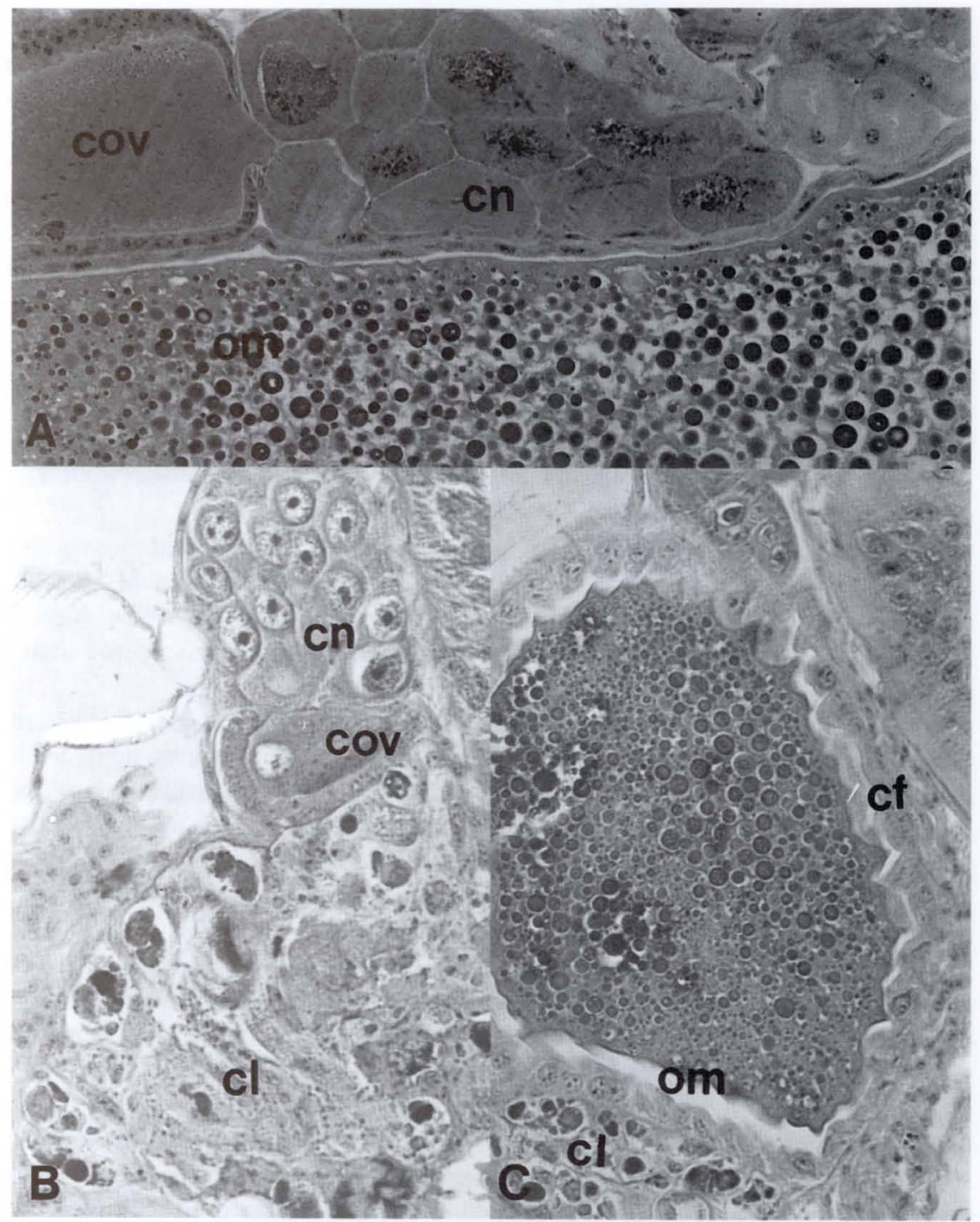

Fig. 5. Ovários de operárias nutridoras e campeiras de Scaptotrigona postica. (A) Porção do vitelário do ovário de uma operária nutridora mostrando um ovócito praticamente maduro (om) e outro em desenvolvimento vendo-se a câmara ovocítica (cov) e a câmara nutridora (cn); (B) porção do ovário de uma operária campeira vendo-se um corpo lúteo (cl) e um ovócito em crescimento com câmara ovocítica (cov) e câmara nutridora (cn).; (C) ovócito maduro (om) em operária campeira. (cf) Células foliculares.

S. postica a diferenciação é tardia porque a diferença na alimentação só acontece no fim da vida larval.

As taxas de morte e divisão celulares são as responsáveis pela diferença entre os ovários nas castas de S. postica a partir da pupação. A taxa de divisão celular é maior 
nas rainhas e a de morte celular nas operárias. Enquanto em A. mellifera a morte celular promove o desaparecimento de ovaríolos, em $S$. postica a morte celular ocorre quando os ovaríolos já estão diferenciados atingindo as células apicais destes nas larvas de operárias, provocando seu encurtamento, enquanto na rainha o crescimento prossegue. Mesmo assim, nota-se que nas pupas de olhos marrons e adultos recém-emergidos de rainhas, o maior comprimento dos ovaríolos deve-se ao filamento terminal muito longo. Contudo, como as divisões celulares continuam nas rainhas recém-emergidas, o interior dos filamentos terminais vai sendo preenchido.

Outra diferença entre $A$. mellifera e $S$. postica é que nesta última espécie, as operárias sempre põem ovos, os quais são dados como alimento à rainha (ovos tróficos) ou se desenvolvem em machos (ovos funcionais), enquanto em A. mellifera isto raramente ocorre. Assim os ovários das operárias de $S$. postica sempre são funcionais não apresentando a rainha um efeito inibidor sobre o desenvolvimento ovariano das operárias (CRUZ-LANDIM 2000).

O ovário das abelhas é do tipo meroístico politrófico, no qual os ovaríolos apresentam três regiões distintas do ápice para a base: filamento terminal, germário e vitelário. O vitelário dos ovários politróficos se caracteriza por seus folículos serem constituídos por ovócitos e células nutridoras, os quais nas abelhas ocupam câmaras distintas: câmara ovocítica e câmara nutridora.

Quando a rainha emerge, aparentemente ainda não há nenhum folículo diferenciado no seu ovário, isto é, ainda não se diferencia um vitelário no ovaríolo, apenas o germário está presente, contendo numerosos cistos. Nos ovários das pupas pigmentadas de operárias, já se observam folículos diferenciados nos ovaríolos, portanto, desde esta fase, vitelário e germário já estão diferenciados, talvez porque as operárias sempre desenvolvem seus ovários e realizam postura durante a fase de nutridora que se inicia por volta de cinco dias de vida adulta.

A operária, em geral, possui um único folículo em estágio de desenvolvimento avançado, às vezes dois, um em cada ovário, sendo capaz de produzir somente poucos ovócitos. A operária pode produzir um ou dois ovos em sua vida, sendo que o número de ovos tróficos é maior do que o de ovos funcionais. Quando dois ovócitos estão se desenvolvendo em ovaríolos opostos eles provavelmente serão do tipo alimentar ou um será trófico e o outro funcional (STAURENGO-DA-CUNHA 1977).

Os ovos tróficos são morfologicamente diferentes dos funcionais (KOEDAM et al. 1996) e possuem também um conteúdo diferente. Estes ovos aparentam ser menos maduros do que os ovos funcionais (CRUZ-LANDIM \& CRUZ-HöFLING 1971; KOEDAM et al. 1996). Os ovócitos com vitelo mais disperso e vacuolizado, são provavelmente ovos tróficos. O córion fino, menos estruturado, frágil e com alterações no formato pode facilitar a digestão ou liberação do conteúdo do ovo para digestão (CRUZ-LANDIM 2000).

Segundo STAURENGO-DA-CunHA (1977) o maior desenvolvimento dos ovários e também a possibilidade das operárias botarem ovos acontece quando estas trabalham na área de cria, com a função de aprovisionar os alvéolos onde a rainha botará seus ovos (operárias e nutridoras), condizendo com os resultados de SAKAGAMI \& ZUCCHI (1963), BEIG (1972). No entanto, neste trabalho verificou-se que 
ovócitos presentes em algumas operárias campeiras apresentavam vitelo mais compactado indicando a formação de um ovo funcional.

Seria lógico esperar que operárias nutridoras, mais jovens, quando sob influência da rainha, fossem estimuladas a botar ovos tróficos para alimentação desta, enquanto, operárias mais velhas poderiam desenvolver ovos funcionais. Esta visão está de acordo com achados de CRUZ-LANDIM \& Hofling (1971) e KOEDAM et al. (1996) que verificaram que os ovos tróficos têm características de imaturidade e com a presença de ovócitos, provavelmente funcionais, nas operárias campeiras. Trabalho não publicado de KOEDAM \& VELTHIUS mostra que em Melipona bicolor (Lepeletier, 1836, Apidae) as operárias que botam ovos funcionais são as que operculam os alvéolos depois da postura da rainha. Pode acontecer que estas operárias sejam ligeiramente mais velhas que aquelas que fazem o aprovisionamento e se achem na transição das tarefas internas do ninho, para as externas (campeiras). Essa interpretação é reforçada pelo fato das operárias campeiras velhas apresentarem ovários com ovaríolos disformes, onde a distinção entre os diferentes tipos celulares é imprecisa, característica da degeneração de todo o órgão.

Neste estudo foi também possível observar, em operárias nutridoras e campeiras a presença de corpos lúteos, os quais se formam a partir da degeneração das células foliculares, depois da ovulação, confirmando a realização de postura por estas operárias.

As diferenças entre $A$. mellifera e $S$. postica quanto ao momento de diferenciação dos ovários e provavelmente outras características das castas respondem pelo resultado obtido com a aplicação de hormônio juvenil em operárias de último estágio, a qual leva ao aparecimento de rainhas em $S$. postica (CAMPOS et al. 1975) e não tem o mesmo efeito em $A$. mellifera, produzindo quando muito intercastas (MICHENER 1974).

AGRADECIMENTOS. As autoras agradecem ao CNPq pelo suporte financeiro.

\section{REFERÊNCIAS BIBLIOGRÁFICAS}

BeEtSMA, J. 1979. The process of queen-worker differentiation in the honeybee. Bee World 60 (1): 24-39.

BEGo, L.R. 1982. On social regulation in Nannotrigona (Scaptotrigona) postica Latreille, with special reference to male production cycles (Hymenoptera, Apidae, Meliponinae). Bol. Zool. Univ. São Paulo, São Paulo, 7: 181-196.

BEIG, D. 1972. The production of males in queenright colonies of Trigona (Scaptotrigona) postica. Jour. Apic. Res., 11 (1): 33-39.

Campos, L.A.O.; F.M. Velthuis \& H.H.W. Velthuis-Kluppel. 1975. Juvenile hormone and caste determination ins tingless bee. Naturwiss. 2: 98-99.

Cruz-Landim, C. 2000. Ovarian development in Meniponine bees (Hymenoptera: Apidae): the effect of queen presence and food on worker ovary development and egg production. Genet. Mol. Biol. 23 (1): 83-88.

CRuz-LANDim, C. \& M.A. CRuZ-Höfling. 1971. Cytochemical and ultrastructural studies on eggs from workers and queen of Trigona. Rev. Brasil. Pesqui. Méd. Biol. 4: 19-25. 
Dixon, S.E. \& R.W. SHuEL. 1963. Studies in the mode of action of royal jelly in honeybee development. III. The effect of experimental variation in diet on growth and metabolism of honeybee larvae. Can. Jour. Zool. 41: 733-739.

FREE, J.B. 1980. A organização social das abelhas (Apis). São Paulo, Edusp, 78p.

Koedam, D.; P.H. Velthuis; T.V.D. KrifT; M.R. Dohmen \& M.J. Sommener. 1996. Morphology of reproductive and trophic eggs and their controlled release by workers in Trigona (Tetragonisca) angustula. Illiger (Apidae, Meliponinae). Physiol. Entomol. 21: 289-296.

Michener, C.D. 1974. The social behavior of bees: A comparative study. Cambridge, The Belknap Press Harvard University, 404p.

RACHINSKY, A. \& W. ENGELS. 1995. Caste development in honeybees (Apis mellifera): juvenile hormone turns on ecdysteroids. Naturwiss 82: 378-379.

RACHINSKY, A. \& K. HARTFELDER. 1990. Corpora allata, a prime regulating element for caste-specific juvenile hormone titre in honeybee larvae (Apis mellifera carnica). Jour. Insect Physiol. 36:189-194.

1991. Differential production of juvenile hormone and its desoxy precursor by corpora allata of honeybees during a critical caste development. Naturwiss 78: 270-272.

Reginato, R.D. \& C. CRUZ-Landim. 2001. Differentiation of the worker's ovary in Apis mellifera L. (Hymenoptera, Apidae) during life of larvae. Invert. Reprod. Develop. 39 (2):127-134.

2002. Morphological Characterization of cell death during the ovary differentiation in worker honeybee. Cell Biol. Internat. 26 (3): 243-251.

- 1998. Desenvolvimento ovariano em larvas de operárias de Apis mellifera L. (Hymenoptera, Apidae). Anais Terceiro Encontro sobre Abelhas, Ribeirão Preto, p.122-127.

REMBoLd, H. 1987. Caste differentiation of the honeybee, fourteen years of biochemical research at Martinsried, p. 3-13. In: J. EDER \& H. REMBOLD (Eds). Chemistry and Biology of Social Insects. München, Verlog Peperny.

RibBand, C.R. 1953. The behavior and social life of honeybees. Bee Res. Ass., London: 352.

Sakagami, S.F. 1982. Stingless bees, p. 316-423. In: R.H. Hermann, (Ed) Social insects. New York, Academic Press, Vol. 3.

SAKAGAmi, S.F. \& R. ZuCCHI. 1966. Ovoposition process in a stingless bee Trigona (Scaptotrigona) postica Latreille (Hymenoptera). Stud. Entomol. 6 (1-4): 497-510.

1966. Estudo comparativo do comportamento de várias espécies de abelhas sem ferrão, com especial referência ao processo de aprovisionamento e postura das células. Ci. Cult., São Paulo, 18 (3): 283-296.

SaKagami, S.F.; D. Beig; R. Zucchi \& Y. AKahIRA. 1963. Occurrence of Ovary-developed workers in Queenright colonies of Stingless Bees. Rev. Brasil. Biol., Rio de Janeiro, 23: 115-192.

SiLvA, D.L.N. 1977. Estudos bionômicos em colônias mistas de Meliponinae (Hymenoptera, Apidae). Bol. Zool., São Paulo, 2: 7-106.

SNOdGRASs, R.E. 1956. Anatomy of the honeybee. Ithaca, Comstock Publishing Associates, 334p.

Sommeijer, M.J.; T.X. China \& F.J.A. MeEuwSEN. 1999. Behavioral data on the production of males by workers in the stingless bee Melipona favosa (Apidae, Meliponinae). Insect Sociaux 46: 92-93.

SOMMEIJER, M.J. \& N.W.M. VAN BUREN. 1992. Male production by laying workers in queenright colonies of Melipona favosa (Apidae, Meliponinae), p. 64-72. In: J. BILlEN (Ed). Biol. evolut. Soc. insect. Leuven, University Press.

SOMmeijer, M.J.; J.W. van VeEn \& R. Sewmar. 1990. The intranidal activity of males of Melipona with some remarks about male production in stingless bees. Actes Coll. Insect. Sociaux 6: 63-67.

Staurengo-DA-Cunha, M.A. 1977. Ovarian development in Scaptotrigona postica Latreille (Hymenoptera, Apidae)- I. Morphological study. Dusenia 10 (4): 205- 215.

VAN VeEn, J.W.; H. ARCE \& M.J. SommeiJer. 1990. Tropical bee-keeping: The production of males in stingless bees (Melipona). Proc. Exp. Appl. Entomol., Amsterdam, 1: 171-176.

Recebido em 11.III.2002; aceito em 06.VII.2002. 